\title{
Primary Central Nervous System Lymphoma in the Elderly
}

\author{
Michael Weller \\ Neurologische Klinik, Universitätsspital Zürich, Switzerland
}

Higher age has consistently been identified as a negative prognostic factor in patients with primary central nervous system lymphoma (PCNSL). The inferior outcome in the elderly has often been attributed to less intensive treatment being administered, but beyond that, there seems to be a fundamental difference in the response to - or benefit from treatment in the elderly. In the G-PCNSL-SG-1 trial [1], 126 of 526 eligible patients were aged 70 or older. Their overall response rate was only mildly lower than in the younger patients, with $44 \%$ as opposed to $57 \%(p=0.016)$. The most notable difference, which accounted for the overall inferior outcome, was the duration of progression-free life in patients achieving a complete response: it was 35 months in the younger patients compared to 16.1 months in the elderly $(p=0.024)$. Less intensive treatment at recurrence may further contribute to the poorer outcome [2]. The biological basis for early recurrence after complete responses in the elderly remains obscure, but may involve host rather than tumor factors.

In the present issue of Oncology Research and TreatMENT, Lee and colleagues from Japan report on 'Prognosis factors in Japanese elderly patients with primary CNS lymphoma treated with non-radiation, intermediate-dose methotrexate-containing regimen' [3]. This is an extension of a previously published series [4]. The authors adopted the current trend of omitting whole brain radiotherapy from the primary treatment of these patients [5], and treated their patients with an 'intermediate dose' methotrexate-based regimen containing $1 \mathrm{~g} / \mathrm{m}^{2}$ intravenous (i.v.) methotrexate on days 1,10 , and $20,40 \mathrm{mg} / \mathrm{m}^{2}$ i.v. ranimustine on day $1,60 \mathrm{mg} / \mathrm{m}^{2}$ oral procarbacine from days 1 to 7 , and i.v. or oral methylprednisolone at a dose of $120 \mathrm{mg} / \mathrm{m}^{2}$ every other day from days 1 to 20 and then at a dose of $60 \mathrm{mg} / \mathrm{m}^{2}$ from days 21 to 45 . Further, $15 \mathrm{mg}$ methotrexate and $40 \mathrm{mg}$ cytarabine were given intrathecally on days 1, 5, 10 and 15 . This was followed by a similarly designed maintenance therapy. Using this regimen, progression-free survival and overall survival rates at 3 years were $29.8 \%$ and $56.2 \%$. On univariate analysis, an age of
$>75$ years, a Karnofsky performance score of $<70$, an altered mentation and a creatinine clearance of $>90 \mathrm{ml} / \mathrm{min}$ were significantly associated with an inferior outcome. On multivariate analysis, only increased creatinine clearance and altered mentation remained significant.

Although the authors discuss various approaches for interpreting their data, it seems inescapable to conclude that high creatinine clearance (reflecting intact renal function) could only be a negative prognostic factor, because these patients were underdosed with methotrexate. The treatment regimen that they employed has the major weakness that it does not take renal function into account. By contrast, in the G-PCNSL-SG-1 trial, the methotrexate dose was governed by the glomerular filtration rate [1], and we had shown previously that this is definitely feasible in elderly patients with PCNSL [6]. Although only very few of the patients studied by Lee et al. appeared to have received whole brain radiotherapy at progression, the authors reported that they did not observe any delayed neurotoxicity. This is a surprising finding, given that they also used intrathecal chemotherapy; however, the information on how this was assessed was sparse.

In general, it may be that a cut-off age of 60 to define elderly or frail patients is not fully adequate and more intensive regimens with a full methotrexate dose are probably warranted in most patients at least until the age of 70 . For future trials, the necessary age cut-off should probably be supplemented with frailty scores to avoid undertreatment of elderly patients who are able to tolerate standard high-dose methotrexate chemotherapy.

\section{Disclosure Statement}

M.W. has received research grants from Bayer, Isarna, MSD, Merck Serono, Phytopharmaceutical Sciences and Roche and honoraria for lectures or advisory board participation from Isarna, Magforce, MSD, Merck Serono, Pfizer, Roche and Teva. The author declares no conflict of interest.

\section{KARGER \\ Fax +497614520714 \\ Information@Karger.com}

www.karger.com (c) 2014 S. Karger GmbH, Freiburg

2296-5270/14/0378-0376\$39.50/0

Accessible online at:

www.karger.com/ort
Prof. Dr. med. Michael Weller

Neurologische Klinik

Universitätsspital Zürich

Frauenklinikstrasse 26, 8091 Zurich, Switzerland

michael.weller@usz.ch 


\section{References}

1 Thiel E, Korfel A, Martus P, Kanz L, Griesinger F, Rauch M, Röth A, Hertenstein B, Von Toll T, Hundsberger T, Mergenthaler HG, Leithäuser M, Birnbaum T, Fischer L, Jahnke K, Herrlinger U, Plasswilm L, Nägele T, Pietsch T, Bamberg M, Weller M: G-PCNSL-SG-1 randomised phase III trial of high-dose methotrexate with or without whole brain radiotherapy for primary central nervous system lymphoma. Lancet Oncol 2010; 11:1036-1047.

2 Roth P, Martus P, Kiewe P, Möhle R, Klasen H, Rauch M, Roth A, Kaun S, Thiel E, Korfel A, Weller M: Outcome of elderly patients with pri- mary CNS lymphoma in the G-PCNSL-SG-1 trial. Neurology 2012;79:890-896.

3 Lee S, Okoshi Y, Kurita N, Seki M, Yokoyama Y, Koichiro M, Hasegawa Y, Chiba S: Prognosis factors in Japanese elderly patients with primary CNS lymphoma treated with nonradiation, intermediate-dose methotrexate-containing regimen. Oncol Res Treat 2014;37: DOI: 10.1159/000363435.

4 Taoka K, Okoshi Y, Sakamoto N, Takano S, Matsumura A, Hasegawa Y, Chiba S: A nonradiation-containing, intermediate-dose methotrexate regimen for elderly patients with primary central nervous system lymphoma. Int J Hematol 2010; 92:617-623.
Weller M: The vanishing role of whole brain radiotherapy for primary central nervous system lymphoma. Neuro Oncol 2014 Jun 23. pii: nou120. [Epub ahead of print].

6 Jahnke K, Korfel A, Martus M, Weller M, Herrlinger U, Schmittel A, Fischer L, Thiel E, on behalf of the German Primary Central Nervous System Lymphoma Study Group (G-PCNSL-SG): High-dose methotrexate toxicity in elderly patients with primary central nervous system lymphoma. Ann Oncol 2005;16:445-449. 